\title{
Sulfur Poisoning on Rh Nanoparticles but Sulfur Promotion on Its Single-Site Catalyst for Carbonylation
}

\section{Yun (J) Ding ( $\nabla$ dyj@dicp.ac.cn )}

Dalian Institute of Chemical Physics, Chinese Academy of Sciences

\section{Siquan Feng}

Dalian National Laboratory for Clean Energy, Dalian Institute of Chemical Physics, Chinese Academy of

Sciences https://orcid.org/0000-0003-1367-164X

\section{Jiali Mu}

Dalian Institute of Chemical Physics, Chinese Academy of Sciences

\section{Xiangsong Lin}

Jiaxing University

\section{Xiangen Song}

Dalian National Laboratory for Clean Energy, Dalian Institute of Chemical Physics, Chinese Academy of Sciences, Dalian, China

\section{Olga Safonova}

Paul Scherrer Institute https://orcid.org/0000-0002-6772-1414

\section{Maarten Nachtegaal}

Paul Scherrer Institute https://orcid.org/0000-0003-1895-9626

\section{Siyue Liu}

State Key Laboratory of Molecular Reaction Dynamics, Dalian Institute of Chemical Physics, Chinese Academy of Sciences

\section{Qiao Yuan}

Dalian Institute of Chemical Physics, Chinese Academy of Sciences

\section{Xingju Li}

Dalian Institute of Chemical Physics, Chinese Academy of Sciences

\section{Weiqing Zhang}

Dalian Institute of Chemical Physics

\section{Guorong Wu}

Dalian Institute of Chemical Physics

\section{Jiayue Yang}

Dalian Institute of Chemical Physics

\section{Wenrui Dong}


State Key Laboratory of Molecular Reaction Dynamics, Dalian Institute of Chemical Physics, Chinese Academy of Sciences, Dalian https://orcid.org/0000-0002-3640-1821

\section{Xueming Yang}

Dalian Institute of Chemical Physics https://orcid.org/0000-0001-6684-9187

\section{Jingwei Li}

Dalian Institute of Chemical Physics, Chinese Academy of Sciences

\section{Zheng Jiang}

Shanghai Advanced Research Institute https://orcid.org/0000-0003-4297-464X

\section{Physical Sciences - Article}

Keywords: sulfer poisoning, nanoparticle metal catalysts

Posted Date: July 13th, 2021

DOl: https://doi.org/10.21203/rs.3.rs-401859/v1

License: (9) This work is licensed under a Creative Commons Attribution 4.0 International License. Read Full License 


\section{Abstract}

Sulfur poisoning is a challenge for most nanoparticle metal catalysts. A trace amount of sulfur contaminants could result in dramatic catalytic activity reduction or even irreversible deactivation1-5. Therefore, new approaches to enhance the catalyst sulfur-resistance have continuously attracted attention from academia and industry. Herein, a role reversal of sulfur from poison to promotor is presented for an Rh-based heterogeneous catalyst from supported Rh nanoparticles (NPs) to its singlesite catalysts (Rh1/AC, AC: activated carbon) in methanol carbonylation, ethylene and acetylene hydrocarboxylic reaction with a feed containing 1000 ppm H2S (S-feed). In situ free-electron laser/time of flight mass spectrometry (In situ FEL/TOF MS) indicated that H2S could be quickly transformed into catalyst-friendly $\mathrm{CH} 3 \mathrm{SCH} 3$ and/or $\mathrm{CH} 3 \mathrm{SH}$ on the $\mathrm{Rh} 1 / \mathrm{AC}$, which coordinated with the $\mathrm{Rh}$ ions and promoted its methanol carbonylation reaction, possessing a lower energy barrier based on DFT calculations. On the contrary, strong adsorption of H2S on the surface of Rh NPs inhibited the reaction of reactants.

\section{Main Text}

As is well-known, sulfur species bring about great challenges for almost all metal catalysts. Even ppm or $\mathrm{ppb}$ levels of sulfur species in a raw stock-feed can result in dramatic activity reduction of NP metal catalysts, often leading to irreversible deactivation. For example, it has been shown that $13 \mathrm{ppb}$ of $\mathrm{H}_{2} \mathrm{~S}$ could deactivate $\mathrm{Ni} / \mathrm{Al}_{2} \mathrm{O}_{3} \mathrm{NPs}$ catalysts in the methanation reaction ${ }^{6}$ and $7 \mathrm{ppm} \mathrm{H}_{2} \mathrm{~S}$ was reported to lead to $90 \%$ activity loss for Ni-Rh alloy NPs ${ }^{7}$ during methane reforming. The strong adsorption of sulfur on metal NPs was deemed to block the active sites and lead to deactivation ${ }^{1-5,8}$. Accordingly, large efforts have been paid every year to the desulfurization of the raw stock-feeds in order to ensure the long-term activity of the metal catalyst. Therefore, removing sulfur species from the raw feed through expensive and energy intensive technologies or developing a high sulfur tolerance catalyst has been a significant research topic for industry.

Sulfur is not only detrimental to catalytic reactions, sometimes it can also act as a promoter. Recently, thiophene promoted $\mathrm{Au}^{9}$, sulfur promoted $\mathrm{Pd}^{10}$, thiol protected $\mathrm{Au}^{11}$, as well as sulfur promoted $\mathrm{Cu}^{12}$ have been reported. In addition, adjusting the metal NPs size could regulate the effect of sulfur poisoning or S-bonding ${ }^{13,14}$. Small Pt NPs are easy to be poisoned by thiophene in ethylene hydrogenation due to the increased coordinatively saturated surfaces ${ }^{13}$. A strong damped oscillatory size dependence of the adsorption energy for sulfur on facets of Cu nanoclusters from 3 up to sizes of $\sim 300$ atoms is also demonstrated ${ }^{14}$. The limit of NP dispersion is single metal site catalyst, which has drawn much attention due to versatile coordinative ability and efficient catalytic activity ${ }^{15-20}$. Herein, impacts of $\mathrm{H}_{2} \mathrm{~S}$ on Rh NPs and its single-site catalysts during methanol carbonylation will be addressed, respectively. And the process of non-toxic transformation of $\mathrm{H}_{2} \mathrm{~S}$ into $\mathrm{CH}_{3} \mathrm{SCH}_{3}$ and/or $\mathrm{CH}_{3} \mathrm{SH}$ species will be disclosed on the single-Rh-site catalysts. 
Mesoporous carbon, $\mathrm{SiO}_{2}$ and $\mathrm{AC}$ supported $\mathrm{Rh} \mathrm{NPs}$ catalysts (Rh/CMK-3, $\mathrm{Rh} / \mathrm{SiO}_{2}$ and $\mathrm{Rh} / \mathrm{AC}$ ) were separately prepared in the METHODS section. As indicated in Table 1, a severe deactivation from 80 and 100 to 0 mole acetyl $_{1} /\left(m_{\text {ole }} \times\right.$ hh) was obtained for Rh NPs in the Rh/CMK-3 and Rh/SiO ${ }_{2}$ catalysts for methanol carbonylation, respectively, when a normal feed was switched into S-feed. In addition, an initial activity of Rh NPs (Rh/AC) was reduced from 163 to 40 mole $_{\text {acetyl }} /\left(m_{\text {ole }} \times e_{R h} \times h\right)$ in an autoclave reactor and suppressed from 135 to 110 mole $_{\text {acety }} /\left(\right.$ mole $\left._{\mathrm{Rh}} \times \mathrm{h}\right)$ in a fixed-bed reactor, respectively. The activity of $\mathrm{Rh} / \mathrm{AC}$ increased gradually with time on stream up to ca. $3100 \mathrm{~mole}_{\text {acety }} /\left(\right.$ mole $\left._{\mathrm{Rh}} \cdot \mathrm{h}\right)$ in the normal feed due to the atomic dispersion of Rh NPs under the existence of $\mathrm{CH}_{3} \mathrm{l} / \mathrm{CO}$ only on $\mathrm{AC}^{21,22}$ (Extended Figure 1). The strategy was also used to prepare $A C$ supported single-Rh-site catalysts $\left(R h_{1} / A C\right)$ with the molecular structure of $\mathrm{Rh}(\mathrm{CO}){ }_{2} \mathrm{I}_{3}(\mathrm{O}=\mathrm{AC})$, where $\mathrm{O}=\mathrm{AC}$ is the carboxyl oxygen groups on the surface of activated carbon $^{21-23}$ (METHODS). Furthermore, the characterization result of spent Rh/AC in S-feed indicated that $\mathrm{H}_{2} \mathrm{~S}$ could not inhibit the atomic dispersion of Rh NPs (Extended Figure 1b-1h). In contrast, the activity of Rh/AC in S-feed finally reach ca. 3800 mole acetyl $/\left(m_{0} / e_{\mathrm{Rh}} \cdot \mathrm{h}\right)$. Accordingly, it was expectable that the activity increased from 3192 to 3974 mole $_{\text {acetyl }} /\left(m_{\text {ol }} e_{\mathrm{Rh}} \times h\right)$ was consequentially observed on the $\mathrm{Rh}_{1} / \mathrm{AC}$ catalyst in a continuous fixed-bed reactor after using S-feed (Table 1 and Extended Figure 2). More interestingly, a sulfur-promoting activity increase from 2021 to 2353 mole acetyl $/\left(m_{0} e_{\mathrm{Rh}} \times \mathrm{h}\right)$ and from 2016 to 2477 mole $_{\text {acety }} /\left(\right.$ mole $\left._{\mathrm{Rh}} \times \mathrm{h}\right)$ was observed, respectively, on both homogeneous single sites $\left[\mathrm{Rh}(\mathrm{CO})_{2} \mathrm{I}_{2}\right]^{-}$and heterogeneous $\mathrm{Rh}_{1} / \mathrm{AC}$ catalyst after $\mathrm{S}$-feed being introduced into the autoclave reactor. A similar effect of sulfur-poisoning on the Rh NPs and sulfur-promoting on the $\mathrm{Rh} / \mathrm{AC}$ was also observed for ethylene and acetylene hydrocarboxylic reaction in the autoclave reactor (Extended Data Table 1).

The high-resolution transmission electron microscopy (HR-TEM), high-angle annular dark-field scanning transmission electron microscopy (HAADF-STEM) showed only isolated Rh atoms on fresh and spent $\mathrm{Rh}_{1} / \mathrm{AC}$ in both normal feed and S-feed (Figure 1a, Extended Data Figure 3a, 3b and 4). In-situ/ex-situ extended X-Ray absorption fine structure (EXAFS) verified that no bond of Rh-Rh was detected on the $\mathrm{Rh}_{1} / \mathrm{AC}$ before, during or even after the reaction. These indicated a real process of single-sites catalysis in both normal feed and S-feed (Figure 1b-1c, Extended Data Figure 5-6 and Table 2). Due to the small scattering factors of $\mathrm{C}, \mathrm{S}$ and $\mathrm{O}$ in comparison to that of I abundant in the micropores of AC, longer Rhligand distances, and a large structural disorder, the fitting data of in-situ EXAFS characterization cannot reliably identify Rh nearest ligands other than I (or Rh).

X-ray photoelectron spectroscopy (XPS) showed that $\mathrm{Rh}^{3+}$ and $\mathrm{Rh}^{4+}$ existed in spent $\mathrm{Rh}_{1} / \mathrm{AC}$ in $\mathrm{S}$-feed $\left(\mathrm{Rh}_{1} / \mathrm{AC}-\mathrm{SR}\right)$ (Extended Data Figure 7 and Table 3), which exhibited little change comparing with that on spent $\mathrm{Rh}_{1} / \mathrm{AC}$ in normal feed. Meanwhile, the $\mathrm{S} 2 \mathrm{p}_{3 / 2}$ peak ascribed to $\mathrm{Rh}-\mathrm{S}\left(\mathrm{CH}_{3}\right)_{2}$ and $\mathrm{Rh}-\mathrm{SHCH}_{3}$ species emerged at $162.7 \mathrm{eV}$ and $164.3 \mathrm{eV}$ respectively in $\mathrm{Rh}_{1} / \mathrm{AC}$-SR, implying that $\mathrm{H}_{2} \mathrm{~S}$ was preferentially transformed into $\mathrm{CH}_{3}-\mathrm{S}-\mathrm{CH}_{3}$ and $\mathrm{CH}_{3}-\mathrm{SH}$ species ${ }^{24}$. The formation of Rh-S bonds on $\mathrm{Rh}_{1} / \mathrm{AC}-\mathrm{SR}$ might be indirectly evidenced from the IR experiment (Extended data Figure 8). Except for $\mathrm{CO}(\mathrm{m} / \mathrm{z}=28)$ and $1 \cdot(m / z=127)$, a species with $m / z=62$ (probably $\mathrm{CH}_{3} \mathrm{SCH}_{3}$ species), originated from $\mathrm{Rh}_{1} / \mathrm{AC}$-SR, was also 
observed by desorption ionization-time of flight mass spectrometry (LDI-TOF MS) (Extended Figure 9). Based on these combined characterization results, we suggest that the active mononuclear complexes exit as $\left(\mathrm{CH}_{3}-\mathrm{S}-\mathrm{R}\right) \mathrm{Rh}(\mathrm{CO}) \mathrm{I}_{2}(\mathrm{O}=\mathrm{AC})\left(\mathrm{R}=\mathrm{H}, \mathrm{CH}_{3}\right)$ during carnbonylation process on the $\mathrm{Rh}_{1} / \mathrm{AC}-\mathrm{SR}$. Meanwhile, TEM, EDS-mapping, and the XPS of spent Rh/CMK-3 reacted in S-feed suggested that the strong adsorption of $\mathrm{H}_{2} \mathrm{~S}$ on the surface of Rh NPs blocked the adsorption of other reactants via an isolated Rh-S layer NPs (Figure 1d-f, Extended Figure 10-12).

In-situ mass spectra, obtained by free-electron laser-time of flight mass spectrometry (FEL TOF-MS), showed new species at $\mathrm{m} / \mathrm{z}=33,34,47,48$ and 62 from $\mathrm{Rh}_{1} / \mathrm{AC}$ catalyst in S-feed (Figure 2a-2b), which could be assigned to $-\mathrm{SH}, \mathrm{H}_{2} \mathrm{~S},-\mathrm{SCH}_{3}, \mathrm{CH}_{3} \mathrm{SH}$, and $\mathrm{CH}_{3} \mathrm{SCH}_{3}$ species, respectively. Moreover, the obtained results through changing the wavelength of ionization radiation proved that the species of $\mathrm{m} / \mathrm{z}=62$ is $\mathrm{CH}_{3} \mathrm{SCH}_{3}$ (Extended Data Figure 13). Interestingly, the ion peak at $\mathrm{m} / \mathrm{z}=62$ emerged at $373 \mathrm{~K}$ and increased with temperature till $453 \mathrm{~K}$, while that at $\mathrm{m} / \mathrm{z}=34$ rapidly decreased from 313 to $433 \mathrm{~K}$ (Figure 2c), implying quick transformation of $\mathrm{H}_{2} \mathrm{~S}$ to $\mathrm{CH}_{3} \mathrm{SCH}_{3}$. Besides, the reaction of $\mathrm{H}_{2} \mathrm{~S}$ with $\mathrm{CH}_{3} \mathrm{OH}$ or $\mathrm{CH}_{3} \mathrm{I}$ could produce $\mathrm{CH}_{3} \mathrm{SCH}_{3}$ and $\mathrm{CH}_{3} \mathrm{SH}$ on the $\mathrm{Rh}_{1} / \mathrm{AC}$ (Figure $2 \mathrm{~d}$ and $2 \mathrm{e}$ ). Moreover, $\mathrm{CH}_{3} \mathrm{SCH}_{3}$ from the spontaneous reaction of $\mathrm{CH}_{3} \mathrm{I}$ with $\mathrm{H}_{2} \mathrm{~S}$ was also observed (Figure 2f).

In-situ diffuse reflectance infrared Fourier transformation spectroscopy on $\mathrm{Rh}_{1} / \mathrm{AC}$ catalyst in $\mathrm{S}$-feed showed a peak at $\sim 1775 \mathrm{~cm}^{-1}$ ascribed to acetyl species, appearing after reaction for 20 min, earlier than that in the normal feed at 25 min (Extended Data Figure 14a-b), indicating that the existence of sulfur species accelerated the formation of acetyl. Meanwhile, signals of $\mathrm{CH}_{3}$ - or $\mathrm{CH}_{2}$ - groups at about 2967 and $2850 \mathrm{~cm}^{-1}$ were dramatically attenuated in S-feed, suggesting that a portion of $\mathrm{CH}_{3}$ ' species were probably quenched by $\mathrm{H}_{2} \mathrm{~S}$ to form $\mathrm{CH}_{3} \mathrm{SH}$ or $\mathrm{CH}_{3} \mathrm{SCH}_{3}$ species (Extended Data Figure 14c-d) ${ }^{25,26}$. Besides, the in-situ electron paramagnetic resonance spectrometry/electron spin resonance also confirmed that the free radicals species were dramatically quenched during methanol carbonylation on $\mathrm{Rh}_{1} / \mathrm{AC}$ in S-feed (Extended Data Figure 15).

DFT calculations investigated the coordination effect of $\mathrm{CH}_{3} \mathrm{SCH}_{3}$ and $\mathrm{CH}_{3} \mathrm{SH}$ on the $\mathrm{Rh}$ mononuclear complex. The minimum energy of $\left(\mathrm{H}_{2} \mathrm{~S}\right) \mathrm{Rh}(\mathrm{CO}) \mathrm{I}_{3}(\mathrm{O}=\mathrm{AC}),\left(\mathrm{CH}_{3} \mathrm{SH}\right) \mathrm{Rh}(\mathrm{CO}) \mathrm{I}_{3}(\mathrm{O}=\mathrm{AC})$, and $\left(\mathrm{CH}_{3} \mathrm{SCH}_{3}\right) \mathrm{Rh}(\mathrm{CO}) \mathrm{I}_{3}(\mathrm{O}=\mathrm{AC})$ is $3.5,-9.2$ and $-14.9 \mathrm{kcal} / \mathrm{mol}$, respectively, when compared with $\mathrm{Rh}(\mathrm{CO})_{2} \mathrm{I}_{3}(\mathrm{O}=\mathrm{AC})$ (Extended Data Figure 16), suggesting that the new formed $\mathrm{CH}_{3} \mathrm{SH}$ and $\mathrm{CH}_{3} \mathrm{SCH}_{3}$ species from $\mathrm{H}_{2} \mathrm{~S}$ favored to coordinate with Rh mononuclear complex to obtain a more stable Rh mononuclear structure. Moreover, the bond length of $\mathrm{CH}_{3}$-l in the chemical adsorption structure of [1-$\mathrm{CH}_{3}-(\mathrm{SR}) \mathrm{Rh}(\mathrm{CO}) \mathrm{I}_{2}(\mathrm{O}=\mathrm{AC})$ ] with $\mathrm{H}_{2} \mathrm{~S}, \mathrm{CH}_{3} \mathrm{SH}$ or $\mathrm{CH}_{3} \mathrm{SCH}_{3}$ species, is $2.15 \AA$, a little longer than that in [I$\left.\mathrm{CH}_{3}-\mathrm{Rh}(\mathrm{CO})_{2} \mathrm{I}_{2}(\mathrm{O}=\mathrm{AC})\right]^{\#}\left(2.13 \AA\right.$ ) (Extended Data Figure 17), implying that the coordination of $\mathrm{H}_{2} \mathrm{~S}, \mathrm{CH}_{3} \mathrm{SH}$ and $\left(\mathrm{CH}_{3}\right)_{2} \mathrm{~S}$ could lower the chemical adsorption energy of $\mathrm{CH}_{3}$. More importantly, the transition state energy barrier of $\left[\mathrm{I}-\mathrm{CH}_{3}-(\mathrm{SR}) \mathrm{Rh}(\mathrm{CO}) \mathrm{I}_{2}(\mathrm{O}=\mathrm{AC})\right]^{\#}$ is $10.0,10.5$ and $16.5 \mathrm{kcal} / \mathrm{mol}$ for $\mathrm{CH}_{3} \mathrm{SCH}_{3}, \mathrm{CH}_{3} \mathrm{SH}$ and $\mathrm{H}_{2} \mathrm{~S}$ coordination, respectively, while that of $\left[1-\mathrm{CH}_{3}-\mathrm{Rh}(\mathrm{CO})_{2} \mathrm{I}_{2}(\mathrm{O}=\mathrm{AC})\right]^{\#}$ is $16.1 \mathrm{kcal} / \mathrm{mol}$, demonstrating 
that $\mathrm{CH}_{3} \mathrm{SCH}_{3}$ or $\mathrm{CH}_{3} \mathrm{SH}$ coordination as a ligand is beneficial for the $\mathrm{Rh}$ mononuclear complex to lower the energy barrier of $\mathrm{CH}_{3}$ l oxidative addition step, accelerating the reaction rate of methanol carbonylation on the $\mathrm{Rh}_{1} / \mathrm{AC}$ catalyst ${ }^{22,27-30}$ (Figure 3 and Extended Data Figure 18).

In summary, a reversal sulfur poisoning effect from Rh NPs to its single-sites catalyst was reported. The supported Rh NPs was easily poisoned by $\mathrm{H}_{2} \mathrm{~S}$, while the $\mathrm{Rh}_{1} / \mathrm{AC}$ exhibited excellent sulfur-promoting activity for methanol carbonylation. Interestingly, $\mathrm{H}_{2} \mathrm{~S}$ cannot prevent atomic dispersion of Rh NPs on an $\mathrm{AC}$ in the presence of $\mathrm{CH}_{3} \mathrm{l} / \mathrm{CO}$. Similar results were also obtained in ethylene and acetylene hydrocarboxylation. $\mathrm{H}_{2} \mathrm{~S}$ could be rapidly transformed into catalyst-friendly $\mathrm{CH}_{3} \mathrm{SCH}_{3}$ and $\mathrm{CH}_{3} \mathrm{SH}$ ligands on the single-site, while strong adsorption of $\mathrm{H}_{2} \mathrm{~S}$ on Rh NPs formed an isolated Rh-S layer, blocking the adsorption of reactants. It is anticipated that the phenomenon reported here might also be extended to other single-metal-site catalysts in various reactions.

\section{Methods}

\section{Catalyst preparation}

Mesoporous carbon, $\mathrm{AC}$ and $\mathrm{SiO}_{2}$ supported Rh NPs catalyst (Rh/CMK-3, Rh/AC and $\mathrm{Rh} / \mathrm{SiO}_{2}$ ) with $1 \%$ weight was synthesized by incipient wetness impregnation, followed by dry and calcination, and then reduced by $\mathrm{H}_{2}$ at $573 \mathrm{~K}$ for $2 \mathrm{~h}$. The $\mathrm{Rh}_{1} / \mathrm{AC}$ catalyst ( $\left.1 \mathrm{wt} . \%\right)$ was prepared through the atomic dispersion strategy of metal NPs. Typically, the coconut activated carbon (AC) was grinded to 40-60 mesh and washed with deionized water until the electrical conductibility of the washings is below $20 \mu \mathrm{s} / \mathrm{cm}$, dried in static air at $393 \mathrm{~K}$ for $12 \mathrm{~h}$. Subsequently, the $\mathrm{AC}$ support was impregnated by an aqueous $\mathrm{RhCl}_{3} \bullet \times \mathrm{H}_{2} \mathrm{O}$ solution. After drying under static conditions at $393 \mathrm{~K}$ for $12 \mathrm{~h}$, the catalysts were treated in a three-step procedure: $573 \mathrm{~K}$ for $2 \mathrm{~h}$ in $\mathrm{N}_{2}(100 \mathrm{~mL} / \mathrm{min}), 573 \mathrm{~K}$ for $2 \mathrm{~h}$ in $\mathrm{H}_{2}(100 \mathrm{~mL} / \mathrm{min})(\mathrm{Rh} / \mathrm{AC}$ was obtained in this step) and $513 \mathrm{~K}$ for $2 \mathrm{~h}$ with a mixture of $\mathrm{CO} / \mathrm{CH}_{3} \mathrm{I}$ (CO passed through a bottle filled with $\mathrm{CH}_{3} \mathrm{l}$ at 30 $\mathrm{mL} / \mathrm{min}$ ), respectively. Finally, the samples were cooled to ambient temperature in a flow of $\mathrm{CO}$. The obtained catalysts were denoted as $\mathrm{Rh}_{1} / \mathrm{AC}$.

\section{Catalyst characterization}

The high-resolution transmission electron microscope (HR-TEM) images of the samples were obtained with JEM-2100 equipped with an energy dispersive spectrometer (EDS). The aberration-corrected highangle annular dark-field scanning transmission electron microscopy (HAADF-STEM) images were also recorded using a JEM-ARM200F STEM/TEM instrument with a CEOS probe corrector working at $200 \mathrm{kV}$ to guarantee a resolution of $0.08 \mathrm{~nm}$.

X-ray photoelectron spectroscopy (XPS) characterization was performed using a Thermo Fisher ESCALAB 250Xi, equipped with a monochromated Al Ka X-ray source ( $\mathrm{hu}=1486.6 \mathrm{eV}, 15 \mathrm{kV}, 10.8 \mathrm{~mA}$ ). During data collection, the vacuum and the working pressure were limited to $3 \times 10^{-8} \mathrm{~Pa}$ and $7.1 \times 10^{-5} \mathrm{~Pa}$, respectively. 
In-situ electron paramagnetic resonance spectrometry/electron spin resonance (In-situ EPR/ESR) (Bruker A200) was conducted to monitor the free electrons in samples to identify the effect of $\mathrm{H}_{2} \mathrm{~S}$ on the radicals produced in the reaction. $5 \mathrm{mg}$ sample was placed in a specific in-situ reactor for in-situ methanol carbonylation reaction, and then cooled to $-177^{\circ} \mathrm{C}$ with liquid nitrogen. A magnetic field linear sweep was performed with a fixed frequency of microwave irradiation (concrete parameters: center field: $3300 \mathrm{G}$, sweep width: $6400 \mathrm{G}$, static field: $100 \mathrm{G}$, microwave bridge frequency: $9.5 \mathrm{GHz}$ and the power is set as $10 \mathrm{~mW}$ ). The EPR data was processed and outputted as a 1st derivative of the absorption spectrum. EPR absorption occurs when the irradiation frequency "matches" the energy level separation created by the magnetic field, Boltzmann distribution.

The spent $\mathrm{Rh}_{1} / \mathrm{AC}$ catalyst in normal and S-feed was soaked in ethanol for $6 \mathrm{~h}$ at room temperature to dissolve metal carbonyl on the surface of AC. Ethanol and the scrubbing solution obtained was smeared to a thin slice of $\mathrm{KBr}$. The infrared scanning and signal processing were carried out under normal conditions.

The in situ diffuse reflectance infrared Fourier transform spectroscopy (DRIFTS) measurements were conducted on a VERTEX 80v FTIR spectrometer with a mercury cadmium telluride (MCT) detector cooled by liquid nitrogen. Catalysts were loaded into a PIKE High Temperature Reaction chamber (ZnSe windows). Mass flow controllers were used to control the gas rates across the reactor bed. For each DRIFTS experiments, the catalyst was first calcined in $\mathrm{He}(40 \mathrm{~mL} / \mathrm{min})$ at $573 \mathrm{~K}$ for $30 \mathrm{~min}$. Then, the temperature of the catalyst was reduced to $513 \mathrm{~K}$ followed by flowing reaction gas. $\mathrm{CH}_{3} \mathrm{OH}, \mathrm{CH}_{3}$ or liquild $\mathrm{CH}_{3} \mathrm{I}$ and $\mathrm{CH}_{3} \mathrm{OH}$ mixtue $\left(30 \mathrm{wt} \% \mathrm{CH}_{3} \mathrm{l}\right)$ were bubbled by reaction gas $\left(\mathrm{CO}, \mathrm{CO} / \mathrm{H}_{2}, \mathrm{He}\right)$ at $298 \mathrm{~K}$. During the reaction, spectra were recorded between $800 \mathrm{~cm}^{-1}$ to $4000 \mathrm{~cm}^{-1}$ by averaging 64 scans at a resolution of 4 $\mathrm{cm}^{-1}$ to improve the signal to noise ratio.

The in situ flow-tube free-electron laser time of flight mass spectrometry (In situ FEL/TOF MS) were conduct at Dalian Coherent Light Source ${ }^{31-34}$ to detect the intermediates and the radicals during methanol gas phase carbonylation reaction. Laser desorption ionization/time of flight mass spectrometry (LDI-TOF MS) was conducted to detect the dissociative fragment of spent $\mathrm{Rh}_{1} / \mathrm{AC}$ catalyst in normal and $S$-feed and further identify its single complex structure. And the in-situ formed short-lived intermediate species were also detected with the same TOF-MS instrument. Experiments on a series of ultraviolet wavelengths, i.e., $112 \mathrm{~nm}, 115 \mathrm{~nm}, 118 \mathrm{~nm}, 125 \mathrm{~nm}, 140 \mathrm{~nm}, 150 \mathrm{~nm}$, were performed according to the ionization energy of intermediate species. For the LDI-TOF MS experiments, $266 \mathrm{~nm}$ lasers were slightly focused on the sample. The skimmed He atom beam passed the sample surface with a distance of $\sim 1 \mathrm{~mm}$ to carry the dissociated and sputtering species to the detection chamber.

The in situ EXAFS (In situ EXAFS) measurements were performed at the SuperXAS beamline at the Swiss Light Source ${ }^{35-38}$. The ring was operated in top-up mode with $400 \mathrm{~mA}$ of $2.4 \mathrm{GeV}$ electrons, which emitted polychromatic radiation in a super bend magnet $(2.9 \mathrm{~T})$ with a critical energy of $11.9 \mathrm{keV}$. The beam was collimated by a Pt-coated mirror and then monochromatized using a channel-cut $\mathrm{Si}(311)$ crystal in the 
QEXAFS monochromator. A rotation speed of $1 \mathrm{~Hz}$ was chosen, yielding one EXAFS spectrum each 500 ms. The samples were measured in transmission mode with a 15-cm ionization chamber filled with $\mathrm{Ar}$ in front of the sample and another $15-\mathrm{cm}$ ionization chamber filled with $\mathrm{Kr}$ behind the powder sample. A third $30-\mathrm{cm}$ ionization chamber filled with Ar was used to measure an Rh metal foil located between the second and a third chamber to obtain an absolute calibration value for the energy scale of each spectrum. This value was related to the relative position of the monochromator crystal, which was measured simultaneously to each data point with a fast optical angular encoder system, yielding an accurate energy scale for the time-resolved spectra. The ionization chambers were operated with a high voltage of $1.5 \mathrm{kV}$, and the signals were amplified with Keithley 428 current amplifiers and then measured with a national instrument DAC data acquisition board using a fast data acquisition software. The $\mathrm{Rh}_{1} / \mathrm{AC}$ catalyst was held between 2 quartz wool plugs and placed in a stainless steel flow reactor with quartz flow reactor. The following gases: $\operatorname{Ar}\left(\mathrm{N}_{2}\right), \mathrm{CO}(50 \%$ in $\mathrm{Ar}), \mathrm{H}_{2}(50 \%$ in $\mathrm{Ar})$, and $1000 \mathrm{ppm}_{2} \mathrm{~S}$ in $\mathrm{Ar}$ were supplied by digital mass-flow controllers. $\mathrm{CH}_{3}$ land methanol vapor were prepared by bubbling $\mathrm{CO}$ through liquid $\mathrm{CH}_{3} \mathrm{I}$ and methanol mixture $\left(30 \mathrm{wt} \% \mathrm{CH}_{3} \mathrm{I}\right)$. The reaction was started by introducing the $\mathrm{CO}$, $\mathrm{CH}_{3} \mathrm{ICH} \mathrm{CH}_{4} \mathrm{OH}, \mathrm{H}_{2}$, and $\mathrm{H}_{2} \mathrm{~S}$ mixture at 1 bar when the reactor temperature increased to $240{ }^{\circ} \mathrm{C}$ in vacuum conditions. We recorded data when the reactants mixture passed through the catalyst.

Ex-situ extended X-ray absorption fine structure (EX-situ EXAFS) data of Rh K-edge were collected at beamline BL14W1 of Shanghai Synchrotron Radiation Facility (SSRF) ${ }^{39,40}$. The sample was grinded into 400 meshes and pressed into a small slice with a size of $0.5 \mathrm{~cm} \times 0.5 \mathrm{~cm}$ before mounted to the test site. The data were recorded in the fluorescence mode equipped with an Electro-Lytle detector, and the calibration energy is $22117 \mathrm{eV}$. The original EXAFS data were processed with Athena software and normalized with the energy of $23220 \mathrm{eV}$, and then analyzed by the Artemis software package. Fourier transformation was applied to process the $k^{3}$-weighted raw data. The theoretical scattering amplitude and phase-shift functions of all the paths for fitting the EXAFS data were calculated with FEFF6 code. Paths of Rh-CO, Rh-I, Rh-Rh were based on the crystal structure of $\left[\mathrm{C}_{4} \mathrm{I}_{2} \mathrm{O}_{4} \mathrm{Rh}_{2}\right]$ and Rh Fm-3m. The .cif files could be found in the database of crystallography open database (COD) with the number of $2202025,2202025,2100454$, respectively. The Reffs of Rh-CO, Rh-I, Rh-Rh were calculated with single scatting at $1.854 \AA, 2.621 \AA$ and $2.539 \AA$, respectively, according to the .cif files mentioned above. Rh-OAC was set with Reff of $2.2 \AA$ according to the first quick shell path based on DFT calculated models.

\section{Density function theory (DFT) calculation}

The activate carbon (AC) model was constructed with carbonyl group based on the molecule geometry of Graphene-like structure. The all-molecular structures were optimized by the density function theory (DFT) calculation using Vienna ab initio simulation package (VASP) $)^{41-44}$. The Perdew-Burke-Ernzerhof (PBE) was used as the exchange correlation function ${ }^{45}$. The cut off kinetic energy was set to $420 \mathrm{eV}$. Brillouin zone integration was approximated using the Monkhorst-Pack k-points method ${ }^{46}$ and set as $1 \times 1 \times 1$. The height of vacuum slab was selected with $12 \AA$ to eliminate the size error. Geometries were optimized until the energy was converged to $1.0 \times 10-4 \mathrm{eV} /$ atom and the force was converged to $0.05 \mathrm{eV} / \AA \AA$. Here, it 
is need to note that the transition states were optimized using the Dimer method. To understand and account for dispersion effect in the entire reaction process, the energy corrections of van der Waals (vdW) were calculated using the semiempirical approach proposed by Grimme ${ }^{47}$ (DFT-D2 method) in conjunction with the PBE functional. All the stable molecule geometries and the transition state structures of $\mathrm{Rh}_{1} / \mathrm{AC}$ complexes were checked by the frequency calculations without imaginary frequency and with one imaginary frequency, respectively. In this study, the unit of molecule bond length or distance between atoms is angstrom.

\section{Catalyst evaluation}

The methanol carbonylation activity test of $\mathrm{Rh} / \mathrm{AC},\left[\mathrm{Rh}(\mathrm{CO})_{2} \mathrm{I}_{2}\right]^{-}$and $\mathrm{Rh}_{1} / \mathrm{AC}$ were conducted in highpressure zirconium reactor $(25 \mathrm{ml})$. The specific reaction conditions were noted below in Table 1 . The $1 \mathrm{wt} \% \mathrm{Rh} / \mathrm{AC}, \mathrm{Rh}_{1} / \mathrm{AC}, \mathrm{Rh} / \mathrm{SiO}_{2}$ and $\mathrm{Rh} / \mathrm{CMK}-3$ were also tested in a fixed-bed reactor. $0.3 \mathrm{~g}$ catalyst was placed in the center of the Hastelloy C-276 reactor. The upper and lower space was filled with quartz sand. Upstream from the reactor, the liquid was vaporized and mixed with $\mathrm{CO} / \mathrm{H}_{2}$ or $\mathrm{CO} / \mathrm{H}_{2} / \mathrm{H}_{2} \mathrm{~S}$ in a Hastalloy tube wrapped with heat tape maintained at $513 \mathrm{~K}$. The tailed gas was chilled at $278 \mathrm{~K}$ to collect the liquid product. Incondensable gas was analyzed using on-line gas chromatography Agilent 7890B equipped with TCD (chromatographic column: Plot Q), and the collected liquid product was off-line analyzed by FID (chromatographic column: HP-FFAP). The space-time-yield (STY) was calculated based on the total moles of $\mathrm{CH}_{3} \mathrm{COOH}$ and $\mathrm{CH}_{3} \mathrm{COOCH}_{3}$ divided by total moles of Rh per hour.

\section{Declarations}

\section{Extended Data}

Extended data for this paper at XXXX. The data that support the findings in this study are in the published article and/or its extended data files. The data sources are deposited on the generalist repository of figshare, and the accession code is xxxxxxx. The whole datasets are available from the corresponding author on reasonable request as well.

\section{Acknowledgements}

The financial support of this work by the National Key R\&D Program of China (2017YFB0602203), the Strategic Priority Research Program of the Chinese Academy of Sciences, Grant No. XDA21020300 and Grant No XDB17020400, and the National Natural Science Foundation of China (22002156), the international partnership program of the Chinese Academy of Sciences (No. 121421KYSB20170012), the Key Technology Team of the Chinese Academy of Sciences (Grant No.GJJSTD20190002), Chemical Dynamics Research Center (Grant No. 21688102), the Strategic Priority Research Program of the Chinese Academy of Sciences (Grant No. XDB17000000) and the Natural Science Foundation of Zhejiang Province (LY18B060007) and key Laboratory of Yarn Materials Forming and Composite Processing Technology, Zhejiang Province, China. This research used resources of the Dalian Coherent Light Source. 


\section{References}

1 Bartholomew, C. H., Agrawal, P. K. \& Katzer, J. R. in Advances in Catalysis Vol. 31 (eds D. D. Eley, Herman Pines, \& Paul B. Weisz) 135-242 (Academic Press, 1982).

2 Häkkinen, H. The gold-sulfur interface at the nanoscale. Nat. Chem. 4, 443-455 (2012).

3 Theofanidis, S.-A. et al. Effect of Rh in Ni-based catalysts on sulfur impurities during methane reforming. Appl. Catal. B: Environ. 267, 118691 (2020).

4 Zhou, W. et al. Impeding catalyst sulfur poisoning in aqueous solution by metal-organic framework composites. Small Methods 4, 1900890 (2020).

5 Väliheikki, A. et al. Deactivation of $\mathrm{Pt} / \mathrm{SiO}_{2}-\mathrm{ZrO}_{2}$ diesel oxidation catalysts by sulphur, phosphorus and their combinations. Appl. Catal. B: Environ. 218, 409-419 (2017).

6 Bartholomew, C. H., Agrawal, P. K. \& Katzer, J. R. Sulfur Poisoning of Metals. Adv. Catal. 31, 135242 (1982).

7 Theofanidis, S. et al. Effect of Rh in Ni-based catalysts on sulfur impurities during methane reforming. Appl. Catal. B: Environ. 267, 118691 (2020).

8 Hakkinen, H. The gold-sulfur interface at the nanoscale. Nat. Chem. 4, 443-455 (2012).

9 Bailie, J. E. \& Hutchings, G. J. Promotion by sulfur of gold catalysts for crotyl alcohol formation from crotonaldehyde hydrogenation. Chem. Commun., 2151-2152 (1999).

10 Abedi, S. \& Morsali, A. Improved activity of palladium nanoparticles using a sulfur-containing metal-organic framework as an efficient catalyst for selective aerobic oxidation in water. New J. Chem. 41, 5846-5852, doi:10.1039/C7NJ00709D (2017).

11 Zhao, J. et al. Reversible Control of Chemoselectivity in Au-38(SR)(24) Nanocluster-Catalyzed Transfer Hydrogenation of Nitrobenzaldehyde Derivatives. J. Phys. Chem. Lett. 9, 7173-7179 (2018).

12 Rousseau, G. B. D., Bovet, N. \& Kadodwala, M. Sulfur the archetypal catalyst poison? The sulfurinduced promotion of the bonding of unsaturated hydrocarbons on $\mathrm{Cu}(111)$. J. Phys. Chem. B 110, 21857-21864 (2006).

13 Baldyga, L. M., Blavo, S. O., Kuo, C.-H., Tsung, C.-K. \& Kuhn, J. N. Size-Dependent Sulfur Poisoning of Silica-Supported Monodisperse Pt Nanoparticle Hydrogenation Catalysts. ACS Catal. 2, 2626-2629 (2012).

14 Boschen, J. S., Lee, J., Windus, T. L., Evans, J. W. \& Liu, D. Size dependence of S-bonding on (111) facets of Cu nanoclusters. J. Phys. Chem. C 120, 10268-10274 (2016). 
15 Shan, J., Li, M., Allard, L. F., Lee, S. \& Flytzani-Stephanopoulos, M. Mild oxidation of methane to methanol or acetic acid on supported isolated rhodium catalysts. Nature 551, 605-608 (2017).

16 Qiao, B. et al. Single-atom catalysis of $\mathrm{CO}$ oxidation using $\mathrm{Pt}_{1} / \mathrm{FeO}_{\mathrm{x}}$. Nat. Chem. 3, 634-641 (2011).

17 Goodman, E. D. et al. Catalyst deactivation via decomposition into single atoms and the role of metal loading. Nat. Catal. 2, 748-755 (2019).

18 Jones, J. et al. Thermally stable single-atom platinum-on-ceria catalysts via atom trapping. Science 353, 150-154 (2016).

19 Sun, Q. et al. Zeolite-encaged single-atom rhodium catalysts: Highly-efficient hydrogen generation and shape-selective tandem hydrogenation of nitroarenes. Angew. Chem. Int. Ed. 58, 18570-18576 (2019).

20 Shan, J., Li, M., Allard, L. F., Lee, S. \& Flytzani-Stephanopoulos, M. Mild Oxidation of Methane to Methanol or Acetic Acid on Supported Isolated Rhodium Catalysts. Nature 551, 605 (2017).

21 Feng, S. et al. In situ formation of mononuclear complexes by reaction-induced atomic dispersion of supported noble metal nanoparticles. Nat. Commun. 10, 5281 (2019).

22 Feng, S., Lin, X., Song, X., Mei, B. \& Ding, Y. Constructing Efficient Single Rh Sites on Activated Carbon via Surface Carbonyl Groups for Methanol Carbonylation. ACS Catal., 682-690 (2021).

23 Feng, S. et al. Preparation and regeneration of supported single-Ir-site catalysts by nanoparticle dispersion via CO and nascent I radicals. J. Catal. 382, 347-357 (2020).

24 National Institute of Standards and Technology, G. M., 20899 (2000). NIST X-ray Photoelectron Spectroscopy Database. NIST Standard Reference Database Number 20, doi:10.18434/T4T88K (retrieved [20200610]).

25 Ausloos, P. \& Lias, S. G. H2S as a Free-Radical Interceptor in the Gas-Phase Radiolysis and Photolysis of Propane. J. Chem. Phys. 44, 521-529 (1966).

26 Larin, I. K., Messineva, N. A., Spasskii, A. I., Trofımova, E. M. \& Turkin, L. E. Measurement of the rate constants for the reactions of the 10 - radical with sulfur-containing compounds $\mathrm{H}_{2} \mathrm{~S},\left(\mathrm{CH}_{3}\right)_{2} \mathrm{~S}$, and $\mathrm{SO}_{2}$. Kinet. Catal. 41, 437-443 (2000).

27 Gonsalvi, L., Adams, H., Sunley, G. J., Ditzel, E. \& Haynes, A. Steric and electronic effects on the reactivity of $\mathrm{Rh}$ and Ir complexes containing $\mathrm{P}-\mathrm{S}, \mathrm{P}-\mathrm{P}$, and $\mathrm{P}-\mathrm{O}$ ligands. Implications for the effects of chelate ligands in catalysis. J. Am. Chem. Soc. 124, 13597-13612 (2002).

28 Haynes, A. et al. Promotion of iridium-catalyzed methanol carbonylation: Mechanistic studies of the cativa process. J. Am. Chem. Soc. 126, 2847-2861 (2004). 
29 Cavallo, L. \& Solà, M. A theoretical study of steric and electronic effects in the rhodium-catalyzed carbonylation reactions. J. Am. Chem. Soc. 123, 12294-12302 (2001).

30 Zhu, T., Jin, S. \& Xu, M. Rhodium-catalyzed, highly enantioselective 1,2-addition of aryl boronic acids to a-ketoesters and a-diketones using simple, chiral sulfur-olefin ligands. Angew. Chem. Int. Ed. 51, 780-783 (2012).

$31 \mathrm{Li}, \mathrm{G}$. et al. Infrared spectroscopic study of hydrogen bonding topologies in the smallest ice cube. Nat. Commun. 11, 5449 (2020).

32 Zhou, J. et al. Ultraviolet photolysis of $\mathrm{H} 2 \mathrm{~S}$ and its implications for $\mathrm{SH}$ radical production in the interstellar medium. Nat. Commun. 11, 1547 (2020).

33 Chang, Y. et al. Hydroxyl super rotors from vacuum ultraviolet photodissociation of water. Nat. Commun. 10, 1250 (2019).

34 Zhang, B., Yu, Y., Zhang, Y. Y., Jiang, S. \& Yang, X. Infrared spectroscopy of neutral water clusters at finite temperature: Evidence for a noncyclic pentamer. P. Natl. A. Sci. 117, 202000601 (2020).

35 Adrian et al. Time-resolved copper speciation during selective catalytic reduction of NO on Cu-SSZ13. Nat. Catal. (2018).

36 Fabbri, E. et al. Dynamic surface self-reconstruction is the key of highly active perovskite nanoelectrocatalysts for water splitting. Nat. Mater. 16, 925-931 (2017).

37 Charlotte et al. Unravelling structure sensitivity in $\mathrm{CO}_{2}$ hydrogenation over nickel. Nat. Catal. (2018).

38 Petrov, A. W. et al. Stable complete methane oxidation over palladium based zeolite catalysts. Nat. Commun. 9, 2545 (2018).

39 Liu, H. et al. QXAFS system of the BL14W1 XAFS beamline at the Shanghai Synchrotron Radiation Facility. J. Synchrotron radiat. (2019).

40 Luo, Z. et al. Reactant friendly hydrogen evolution interface based on di-anionic MoS2 surface. Nat. Commun. 11, 1116 (2020).

41 Kresse, G. \& Furthmuller, J. Efficient iterative schemes for ab initio totalenergy calculations using a plane-wave basis set. Phys. Rev. B 54, 11169-11186 (1996).

42 Kresse, G. \& Hafner, J. Ab initio molecular-dynamics for liquid-metals. Phys. Rev. B 47, 558-561 (1993). 
43 Kresse, G. \& Hafner, J. Ab-initio molecular-dynamics simulation of the liquidmetal amorphoussemiconductor transition in germanium. Phys. Rev. B 49, 14251-14269 (1994).

44 Kresse, G. \& Furthmuller, J. Efficiency of ab-initio total energy calculations for metals and semiconductors using a plane-wave basis set. Phys. Rev. B 6, 15-50 (1996).

45 Perdew, J. P., Burke, K. \& Ernzerhof, M. Generalized gradient approximation made simple. Phys. Rev. Lett. 77, 3865-3868 (1996)

46 Monkhorst, H. J. \& Pack, J. D. Special points for brillouin-zone integrations. Phys. Rev. B 13, 51885192 (1976).

47 Grimme, S. Semiempirical GGA-type density functional constructed with a long-range dispersion correction. J. Comput. Chem. 27, 1787-1799 (2006).

\section{Table 1}

Table 1. Effect of $\mathrm{H}_{2} \mathrm{~S}$ on the catalytic activity of $\mathrm{Rh}$ NPs ( $\mathrm{Rh} / \mathrm{AC}, \mathrm{Rh} / \mathrm{CMK}-3$ and $\mathrm{Rh} / \mathrm{SiO}_{2}$ ) and mononuclear complexes ([Rh $\left.\left.(\mathrm{CO})_{2} \mathrm{I}_{2}\right]^{-}, \mathrm{Rh}_{1} / \mathrm{AC}\right)$ catalysts. 


\begin{tabular}{|c|c|c|c|c|}
\hline Reaction & $\mathrm{CH}_{3} \mathrm{OH}$ & $+\mathrm{CO}$ & $\stackrel{\text { Catalyst }}{\longrightarrow}$ & $r_{-}^{\mathrm{O}}$ \\
\hline Catal & & Reactor & Conditions & $\mathrm{mol}_{\text {acetyl }} /\left(\mathrm{mol}_{\mathrm{Rh}} \bullet \mathrm{h}\right)$ \\
\hline \multirow{4}{*}{ Rh NPs } & $\mathrm{Rh} / \mathrm{AC}$ & ${ }^{a}$ Autoclave & $\begin{array}{c}\text { Normal feed } \\
\text { S-feed }\end{array}$ & $\begin{array}{l}163^{*} \\
40^{*} \downarrow\end{array}$ \\
\hline & $\mathrm{Rh} / \mathrm{AC}$ & ${ }^{b}$ Fixed-bed & $\begin{array}{c}\text { Normal feed } \\
\text { S-feed }\end{array}$ & $\begin{array}{c}135^{*} \\
110^{\circ} \downarrow\end{array}$ \\
\hline & $\mathrm{Rh} / \mathrm{CMK}-3$ & ${ }^{b}$ Fixed-bed & $\begin{array}{c}\text { Normal feed } \\
\text { S-feed }\end{array}$ & $\begin{array}{l}80^{*} \\
0 * \downarrow\end{array}$ \\
\hline & $\mathrm{Rh} / \mathrm{SiO}_{2}$ & ${ }^{b}$ Fixed-bed & $\begin{array}{c}\text { Normal feed } \\
\text { S-feed }\end{array}$ & $\begin{array}{l}100^{* *} \\
0^{* *} \downarrow\end{array}$ \\
\hline \multirow{3}{*}{$\begin{array}{l}\text { Mononuclear } \\
\text { complexes }\end{array}$} & {$\left[\mathrm{Rh}(\mathrm{CO})_{2} \mathrm{I}_{2}\right]^{-}$} & ${ }^{c}$ Autoclave & $\begin{array}{c}\text { Normal feed } \\
\text { S-feed }\end{array}$ & $\begin{array}{c}2021 \\
2353 \uparrow\end{array}$ \\
\hline & $\mathrm{Rh}_{1} / \mathrm{AC}$ & ${ }^{a}$ Autoclave & $\begin{array}{c}\text { Normal feed } \\
\text { S-feed }\end{array}$ & $\begin{array}{c}2016 \\
2477 \uparrow\end{array}$ \\
\hline & $\mathrm{Rh}_{1} / \mathrm{AC}$ & ${ }^{b}$ Fixed-bed & $\begin{array}{c}\text { Normal feed } \\
\text { S-feed }\end{array}$ & $\begin{array}{l}3015^{* *} \\
3974 \uparrow^{* *}\end{array}$ \\
\hline
\end{tabular}

Reaction conditions: S-feed: $\mathrm{S}$ content 1000 ppm $\mathrm{H}_{2} \mathrm{~S}$, Rh content was 1.0 wt.\% for Rh/AC, Rh/CMK-3ロRh/SiO 2 and $\mathrm{Rh}_{1} / \mathrm{AC} .{ }^{a} 0.2 \mathrm{~g} \mathrm{Rh} / \mathrm{AC}$ and $0.1 \mathrm{~g} \mathrm{Rh} / \mathrm{AC} ; 3.0 \mathrm{MPa} \mathrm{CO}, \mathrm{CH}_{3} \mathrm{OH}\left(218.75 \mathrm{mmol}\right.$ ), $\mathrm{CH}_{3} \mathrm{I}$ (20.98 $\left.\mathrm{mmol}\right)$ for $\mathrm{Rh}_{1} / \mathrm{AC}$ and $3.73 \mathrm{mmol}$ for $\mathrm{Rh} / \mathrm{AC}$, ultra-pure water $(277.8 \mathrm{mmol}), 433 \mathrm{~K}, 20 \mathrm{~min}$ in a zirconium autoclave reactor. ${ }^{b} 0.3 \mathrm{~g}$ catalysts, $513 \mathrm{~K}, 1.7 \mathrm{MPa}, \mathrm{CO} / \mathrm{CH}_{3} \mathrm{OH}=1.0$ (mole ratio), $\mathrm{CO} / \mathrm{H}_{2}=10$ (mole ratio), $\mathrm{CH}_{3} \mathrm{I} / \mathrm{CH}_{3} \mathrm{OH}=1 / 24$ (mass ratio) for $\mathrm{Rh} / \mathrm{AC}, \mathrm{CH}_{3} \mathrm{I} / \mathrm{CH}_{3} \mathrm{OH}=3 / 7$ (mass ratio) for $\mathrm{Rh} / \mathrm{CMK}-3, \mathrm{Rh} / \mathrm{SiO}_{2}$ and $\mathrm{Rh}_{1} / \mathrm{AC}$ in Hastelloy fixed-bed reactor. ${ }^{c} 0.1 \mathrm{~g} \mathrm{RhI} \mathrm{I}_{3}$, $3.0 \mathrm{MPa} \mathrm{CO}, \mathrm{CH}_{3} \mathrm{OH}(81.25 \mathrm{mmol}), \mathrm{CH}_{3} \mathrm{I}(7.82 \mathrm{mmol})$, ultra-pure water $(277.8 \mathrm{mmol}), 433 \mathrm{~K}, 20 \mathrm{~min}$ in a zirconium autoclave reactor. The dispersive rate of $\mathrm{Rh} \mathrm{NP}$ on $\mathrm{Rh} / \mathrm{AC}$ was in proportion to the concentration of $\mathrm{CH}_{3} \mathrm{I}$ and $\mathrm{CO}^{*}$ Initial data obtained after $2 \mathrm{~h}$ on stream in methanol carbonylation. ${ }^{* *}$ Data obtained after $40 \mathrm{~h}$ on stream in methanol carbonylation.

\section{Figures}


a

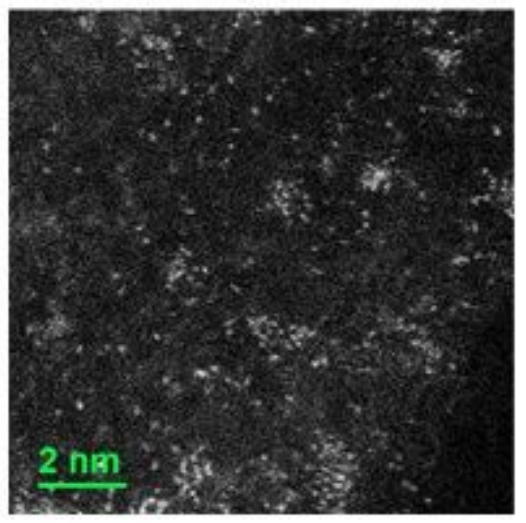

d

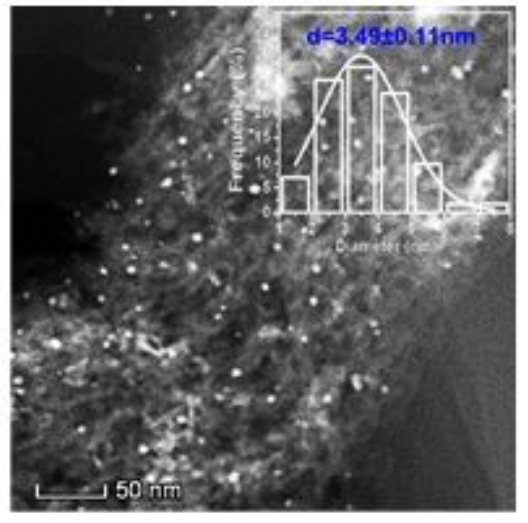

b

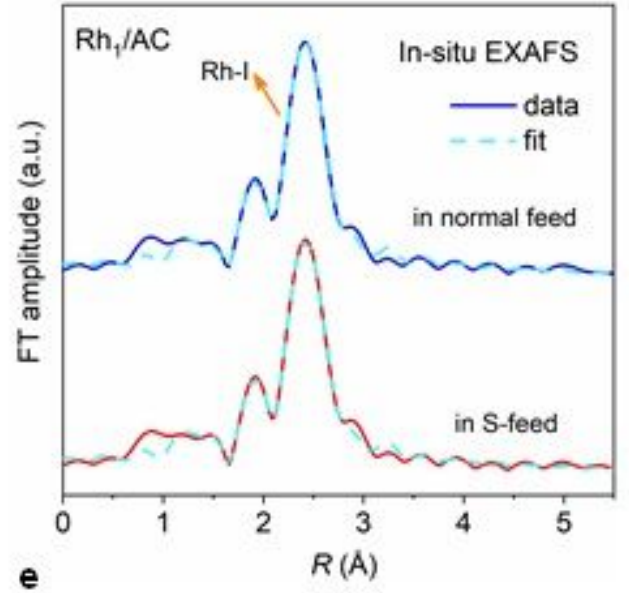

e

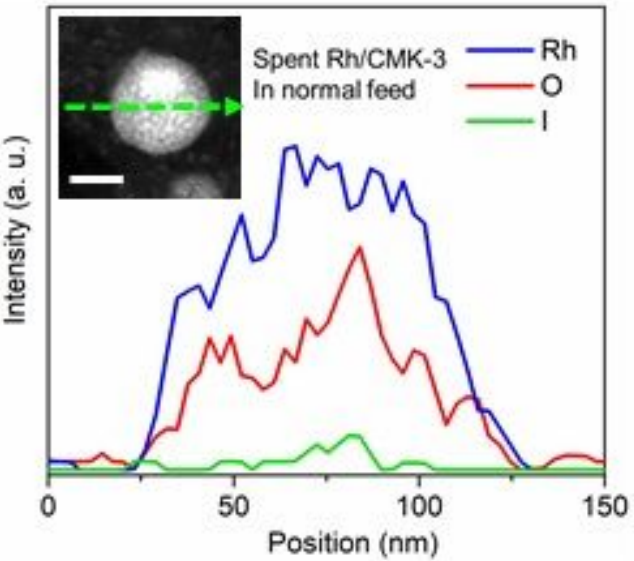

c
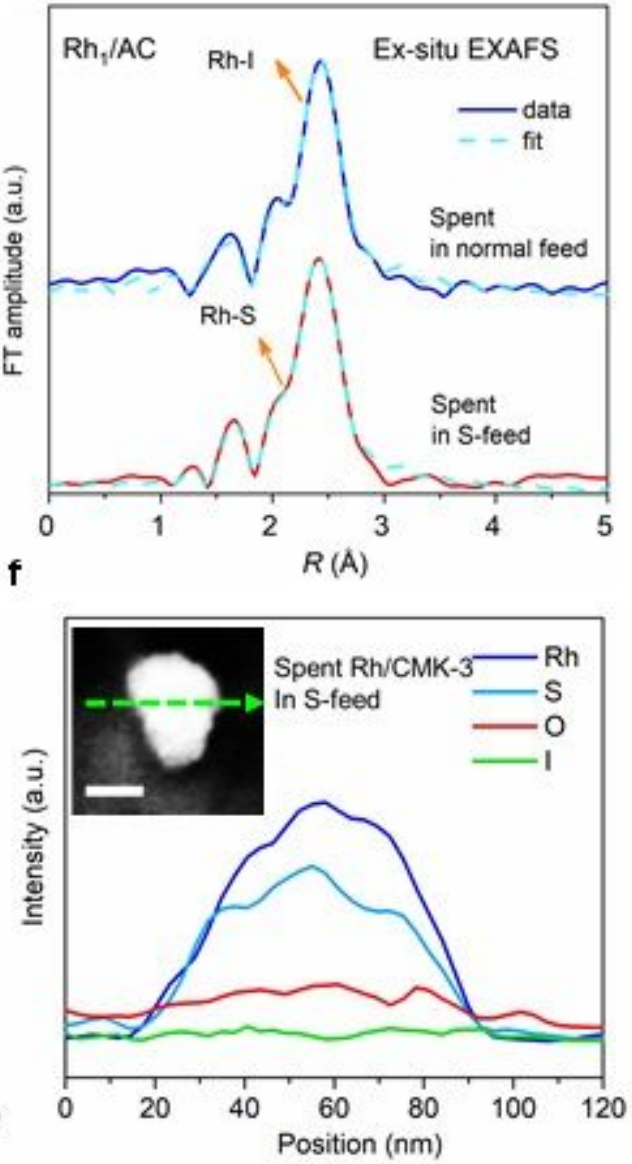

Figure 1

Effect of $\mathrm{H} 2 \mathrm{~S}$ on the structure of Rh1/AC and Rh/CMK-3 catalysts for methanol carbonylation reaction. (a) HAADF-STEM image of spent Rh1/AC in S-feed. (b) The in-situ Rh k-edge EXAFS fitting of 1 h average data of Rh1/AC catalyst in S-feed or normal feed. (c) The ex-situ Rh k-edge EXAFS fitting of spent Rh1/AC catalyst in S-feed or normal feed. (d) HAADF-STEM image of spent Rh/CMK-3 in S-feed, (e) EDS line scanning result of single Rh NPs in the spent Rh/CMK-3 in normal feed, (f) EDS line scanning result of single Rh NPs in the spent Rh/CMK-3 in S-feed. 


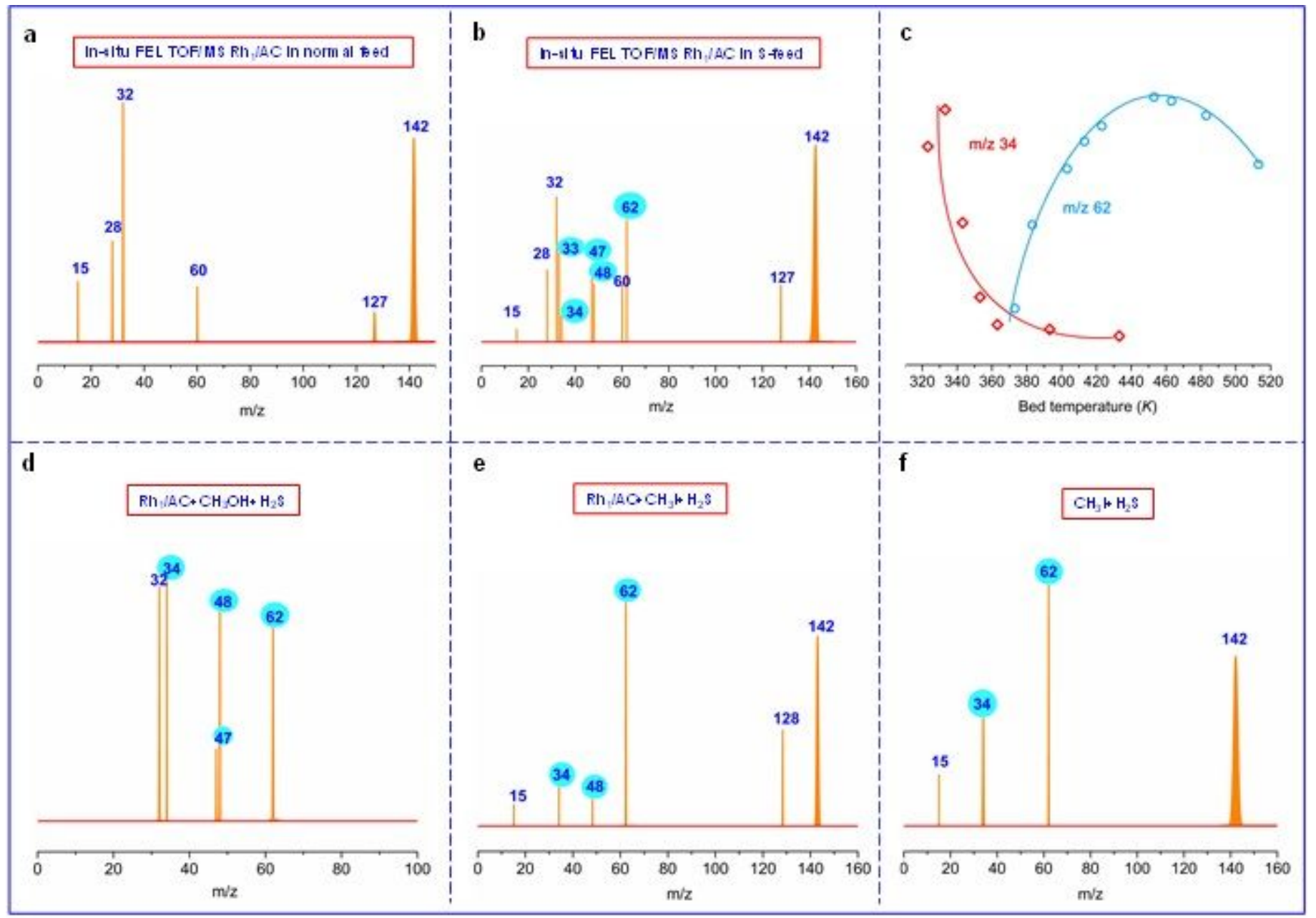

Figure 2

The in-situ FEL/TOF-MS of Rh1/AC for methanol carbonylation in normal feed, S-feed and the comparative experiments. The in-situ free-electron laser time of flight mass spectrum (FEL/TOF MS) of methanol carbonylation on Rh1/AC catalyst in (a) normal feed and (b) S-feed at $513 \mathrm{~K}, 0.1 \mathrm{bar}$, FEL 112 $\mathrm{nm}$ and $40 \mathrm{uJ} / \mathrm{cm} 2$, H2S $10000 \mathrm{ppm}$. (c) The normalized signal intensity of m/z 34 (H2S) and m/z 62 $(\mathrm{CH} 3 \mathrm{SCH} 3)$ as a function of temperature at the condition of (b). (d) The comparative FEL/TOF MS experiment on Rh1/AC catalyst with $\mathrm{CH} 3 \mathrm{OH}$ and $\mathrm{H} 2 \mathrm{~S}$. (e) The comparative FEL/TOF MS experiment on Rh1/AC catalyst with $\mathrm{CH} 3 \mathrm{I}$ and $\mathrm{H} 2 \mathrm{~S}$. (f) The comparative FEL/TOF MS experiment only with $\mathrm{CH} 3 \mathrm{I}$ and $\mathrm{H} 2 \mathrm{~S}$. 


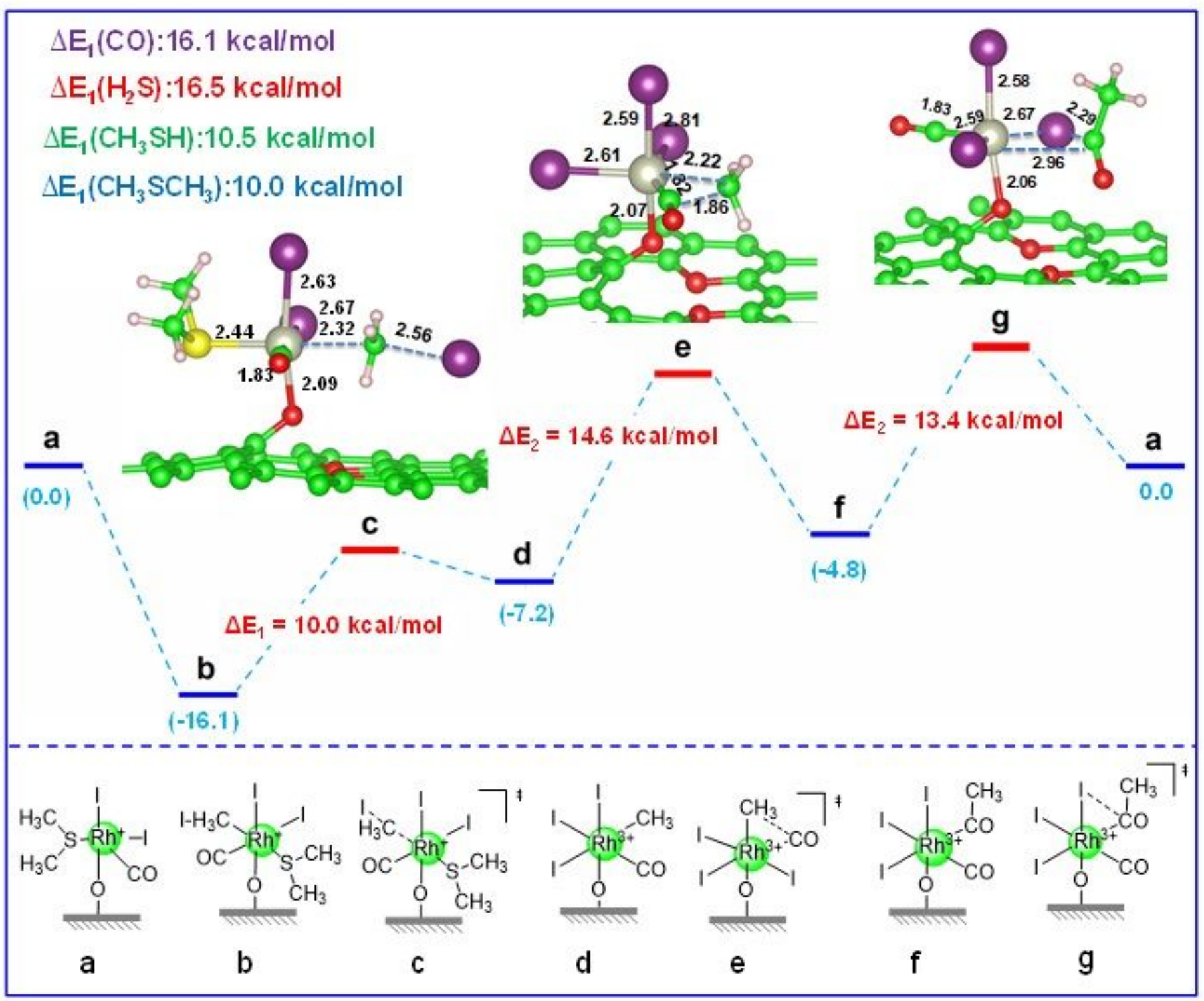

Figure 3

The DFT calculations about the effect of $\mathrm{H} 2 \mathrm{~S}, \mathrm{CH} 3 \mathrm{SH}, \mathrm{CH} 3 \mathrm{SCH} 3$ on the energy barrier of $\mathrm{CH} 3 \mathrm{I}$ oxidative addition on single-site Rh1/AC catalyst, and the energy evolution during the heterogeneous methanol carbonylation. Gray ball represents Rh atom; red ball represents $\mathrm{O}$ atom; purple ball represents I atom; yellow ball represents $\mathrm{S}$ atom; green ball represents $\mathrm{C}$ atom; pink ball represents $\mathrm{H}$ atom.

\section{Supplementary Files}

This is a list of supplementary files associated with this preprint. Click to download.

- ExtendedXXdatafinal.docx 